\title{
HEPARIN MODIFICATION OF A BIOMIMETIC BONE MATRIX MODULATES OSTEOGENIC AND ANGIOGENIC CELL RESPONSE IN VITRO
}

\author{
M. Quade ${ }^{1}$, S. Knaack¹, D. Weber ${ }^{2}$, U. König ${ }^{3}$, B. Paul ${ }^{1}$, P. Simon ${ }^{4}$, A. Rösen-Wolff , R. Schwartz-Albiez ${ }^{2}$, \\ M. Gelinsky ${ }^{1}$ and A. Lode ${ }^{1 *}$
}

\author{
${ }^{1}$ Centre for Translational Bone, Joint and Soft Tissue Research, University Hospital Carl Gustav Carus and Faculty \\ of Medicine, Technische Universität Dresden, Germany \\ ${ }^{2}$ German Cancer Research Centre (DKFZ), Clinical Cooperation Unit Applied Tumour Immunology, \\ Heidelberg, Germany \\ ${ }^{3}$ Leibniz Institute of Polymer Research e. V., Dresden, Germany \\ ${ }^{4}$ Max Planck Institute of Chemical Physics of Solids, Dresden, Germany \\ ${ }^{5}$ Department of Paediatrics, University Hospital Carl Gustav Carus, Dresden, Germany
}

\begin{abstract}
In this study, the effect of heparin-modified collagen type I/hydroxyapatite (HA) nanocomposites on key processes of bone regeneration - osteogenesis and angiogenesis was characterised in vitro. Two approaches were applied for heparin modification: it was either integrated during material synthesis (in situ) or added to the porous scaffolds after their fabrication (post). Cultivation of human bone marrow-derived stromal cells (hBMSC), in heparinmodified versus heparin-free scaffolds, revealed a positive effect of the heparin modification on their proliferation and osteogenic differentiation. The amount of heparin rather than the method used for modification influenced the cell response favouring proliferation at smaller amount (30 mg/g collagen) and differentiation at larger amount ( $150 \mathrm{mg} / \mathrm{g}$ collagen). A co-culture of human umbilical vein endothelial cells (HUVEC) and osteogenically induced hBMSC was applied for in vitro angiogenesis studies. Pre-vascular networks have formed in the porous structure of scaffolds which were not modified with heparin or modified with a low amount of heparin ( $30 \mathrm{mg} / \mathrm{g}$ collagen). The modification with higher heparin quantities seemed to inhibit tubule formation. Pre-loading of the scaffolds with VEGF influenced formation and stability of the prevascular structures depending on the presence of heparin: In heparin-free scaffolds, induction of tubule formation and sprouting was more pronounced whereas heparinmodified scaffolds seemed to promote stabilisation of the pre-vascular structures. In conclusion, the modification of mineralised collagen with heparin by using both approaches was found to modulate cellular processes essential for bone regeneration; the amount of heparin has been identified to be crucial to direct cell responses.
\end{abstract}

Keywords: collagen, heparin, hydroxyapatite, endothelial cells, mesenchymal stem cells, osteogenic differentiation, angiogenesis, co-culture.
*Address for correspondence:

Anja Lode

Centre for Translational Bone, Joint and Soft Tissue Research

University Hospital Carl Gustav Carus and Faculty of Medicine

Technische Universität Dresden, Dresden

Germany

Telephone: +493514586692

Fax: +493514587210

Email: anja.lode@tu-dresden.de

\section{Introduction}

The concept of tissue engineering (TE) provides new approaches for the regeneration of lost or dysfunctional skeletal tissue, promising considerable progress compared to current clinical approaches. The utilisation of the regenerative potential of stem cells in combination with an engineered extracellular matrix (scaffold) and stimulating biological factors is intended to enhance bone formation and hence meet currently unsolved clinical problems (Black et al., 2015). One of the aspects addressed by research is the development of suitable scaffold matrices constituting the physical microenvironment for cells. Their structure and composition should allow cell penetration and support cell adhesion as well as proliferation and differentiation. The natural extracellular matrix (ECM) does not only act as structure for cell anchorage but can also actively provide signalling cues to direct cellular processes, act as reservoir for growth factors and modulate their activity (Rosso et al., 2004; Chan and Leong, 2008). Mimicking the ECM is a common strategy of TE; regarding bone tissue, scaffolds composed of calcium phosphates and collagen type I as well as composites thereof have been proven capable of assisting bone regeneration (Szpalski et al., 2012; Black et al., 2015; Pina et al., 2015; Yunus Basha et al., 2015).

Heparan sulphate proteoglycans are key constituents of the bone ECM, acting as regulators of tissue development and homeostasis (Rodgers et al., 2008). Their functional component is the glycosaminoglycan heparan sulphate which is known to be involved in cell signalling by interacting with various growth factors and cytokines (Brickman et al., 1998; Kreuger et al., 2006). The structurally related heparin, belonging to the same class of sulphated glycosaminoglycans, is clinically used 
as anticoagulant. It is also known to bind specifically many proteins, including growth factors, cytokines and chemokines as well as ECM proteins, and to regulate their activity (Sasisekharan and Venkataraman, 2000; Capila and Linhardt, 2002). Both, heparan sulphate and heparin, have been applied to modify biomaterials in order to create matrices which better mimic the ECM with respect to the ability to bind signalling factors, control their release and modulate their activity (Wissink et al., 2001; Steffens et al., 2004; Benoit and Anseth, 2005; Luong-Van et al., 2007; Nillesen et al., 2007; Calarco et al., 2010; Chen et al., 2010; König et al., 2014; Sanjurjo-Rodriguez et al., 2016).

We have recently described the modification of an artificial bone matrix consisting of mineralised collagen type I with heparin (Knaack et al., 2014). Mineralised collagen can be produced in a biomimetic process of synchronous collagen fibril reassembly and mineralisation (Bradt et al., 1999). The resulting material with the mineral phase, nanocrystalline hydroxyapatite (HA), tightly bound to the collagen matrix resembles the natural counterpart closely. 3D scaffolds with an interconnecting porosity suitable for cell colonisation can be fabricated by freeze-drying of the mineralised collagen suspension and chemical crosslinking (Gelinsky et al., 2008). In vitro studies revealed that this nanocomposite is able to support proliferation and osteogenic differentiation of human bone marrow-derived stromal cells (hBMSC) (Bernhardt et al., 2009). Resorption of the material and new bone formation were observed in vivo (Yokoyama et al., 2005; Scholz et al., 2010). However, two aspects have motivated us to continue the development of our scaffold material: (i) current TE approaches are strongly limited by the lack of vascularisation in the cell-matrix constructs immediately after implantation (Nillesen et al., 2007; Rouwkema et al., 2008). Therefore, the development of strategies for stimulation of angiogenesis is a major goal of research. (ii) In systemically altered bone, the regenerative capacity is strongly reduced, e.g. by a small number of cells or an impaired balance between bone formation and resorption characteristic for osteoporosis. Here, the development of scaffold materials which are able to enrich cells with regenerative potential in the affected area is a promising approach. Both processes, cell attraction and vascularisation, can be stimulated by chemoattractive factors (Richardson et al., 2001; Kanczler et al., 2008; Mishima and Lotz, 2008; Thieme et al., 2009). With the aim of utilising the natural binding properties of heparin for functionalisation of mineralised collagen matrices with such factors, we have developed two approaches for heparin-modification: integration during material synthesis ('in situ') or addition after scaffold-fabrication ('post') (Knaack et al., 2014; König et al., 2014). An enhanced binding capacity for the angiogenic factor VEGF (vascular endothelial growth factor) and a sustained, nearly constant release were proven for scaffolds modified with both approaches (Knaack et al., 2014).

The aim of the present study was to characterise the effect of the heparin-modification on two key processes of bone regeneration in vitro - osteogenesis and angiogenesis. HBMSC were cultivated in heparin-modified (in situ and post) as well as heparin-free scaffolds and their proliferation and osteogenic differentiation were studied. A co-culture of human umbilical vein endothelial cells (HUVEC) and osteogenically induced hBMSC was applied for in vitro angiogenesis studies on the heparin-modified versus unmodified scaffolds; the impact of VEGF loading of the scaffolds on formation and stability of prevascular structures was investigated. For proper evaluation of the cell response, the influence of the heparin-modification on material and scaffold properties was characterised.

\section{Materials and Methods}

\section{Scaffold material and preparation}

Mineralised collagen scaffolds were prepared as described (Gelinsky et al., 2008). Briefly, collagen type I isolated from bovine tendon (kindly provided by Syntacoll, Germany) was pepsin digested and dissolved in $10 \mathrm{mM}$ hydrochloric acid. $0.1 \mathrm{M}$ calcium chloride solution was mixed with the collagen solution and the $\mathrm{pH}$ value was adjusted to 7.0 by addition of $0.5 \mathrm{M}$ TRIS and $0.5 \mathrm{M}$ Sørensen phosphate buffer. After simultaneous collagen fibril reassembly and HA-precipitation at $37^{\circ} \mathrm{C}$ for $12 \mathrm{~h}$ the mineralised collagen fibrils were collected by centrifugation. Resuspended in distilled water, the material was filled into cavities of 96-well plates, frozen at $-20{ }^{\circ} \mathrm{C}$ and freeze-dried. The scaffolds $(\mathrm{d}=6 \mathrm{~mm}, \mathrm{~h}=3-8 \mathrm{~mm})$ were cross-linked with 2 wt\% EDC (1-ethyl-3-(3-dimethyl aminopropyl) carbodiimide; Fluka, Germany) in 80 vol $\%$ ethanol for $1 \mathrm{~h}$. Scaffolds were then washed with $1 \mathrm{wt} \%$ glycine solution and distilled water and finally freeze-dried. Heparinmodification was conducted as described (Knaack et al., 2014): For in situ-integration, heparin (Sigma-Aldrich) was added to the collagen solution immediately before collagen fibril reassembly and mineralisation. For postmodification, heparin (in $50 \mathrm{mM}$ MES (2- $(N$-morpholino) ethanesulfonic acid; Sigma-Aldrich) buffer ( $\mathrm{pH}$ 5.5)) was added to the scaffolds and gently shaken for $24 \mathrm{~h}$ at room temperature. Afterwards, scaffolds were rinsed with MES buffer and distilled water before they were freeze-dried again. Following scaffold variants were used: heparin-free ("0"), heparin-modified by in situ-integration ("I") and by post-modification ("P") with 30, 75 and $150 \mathrm{mg}$ heparin/g collagen, respectively. The scaffolds were sterilised by $\gamma$-irradiation at $25 \mathrm{kGy}$.

\section{Material characterisation}

Fourier transform-infrared (FT-IR) spectroscopy

Freeze dried scaffolds were embedded in $\mathrm{KBr}$ and analysed by FT-IR spectroscopy (FTS 2000; Perkin-Elmer, U.S.A). The detected FT-IR spectra were baseline-corrected and flattened by Savitzky-Golay algorithm with nine supporting points.

\section{Transmission electron microscopy (TEM)}

Small pieces of freeze-dried scaffolds were infiltrated with epoxy resin, which then was polymerised for $72 \mathrm{~h}$ at $60{ }^{\circ} \mathrm{C}$. After trimming the samples for an even surface (EM-TRIM 2; Leica, Germany) the specimens were cut into $70 \mathrm{~nm}$ ultra-thin sections using a Leica UC6 
ultramicrotome (Leica), equipped with a diamond razor (Diatome, Switzerland). The sections were mounted on formvar-coated copper grids (Quantifoil, Germany) and examined with a Tecnai 10 TEM (FEI, U.S.A) at $100 \mathrm{kV}$.

\section{Mechanical characterisation}

Compression properties of the scaffolds $(d=6 \mathrm{~mm}$, $\mathrm{h}=8 \mathrm{~mm}$ ) were evaluated in static mode using a Z010 equipped with a $100 \mathrm{~N}$ load cell (Zwick, Germany). For analysis pre-wetted scaffolds (stored in simulated body fluid (Oyane et al., 2003) for $24 \mathrm{~h}$ prior to testing) were compressed to $50 \%$ of their initial height with a velocity of $0.1 \mathrm{~mm} / \mathrm{s}$. Compressive stress-strain curves were recorded and evaluated with respect to compression modulus (test expert II, Zwick).

\section{Heparin quantification}

The amount of bound heparin was determined by the DMMB-method as described (Knaack et al., 2014). In brief, each scaffold was homogenised and digested in $1 \mathrm{~mL}$ papain-solution $(0.1 \mathrm{mg} / \mathrm{mL}$ in Hank's Balanced Salt Solution; Sigma-Aldrich) for $24 \mathrm{~h}$ at $60{ }^{\circ} \mathrm{C} .100 \mu \mathrm{L}$ of the digestion solution were added to $1.25 \mathrm{~mL} \mathrm{DMMB}$-solution (Müller and Hanschke, 1996) and incubated for $15 \mathrm{~min}$ at room temperature. After spinning down precipitated DMMB-heparin complexes, absorption of the supernatant was measured spectrophotometrically at $590 \mathrm{~nm}$ and correlated to a calibration line.

\section{Cell culture experiments \\ Cells}

Human bone marrow-derived stromal cells (kindly provided by Prof. Bornhäuser; Medical Clinic I, University Hospital Carl Gustav Carus Dresden) were isolated from bone marrow aspirates of three healthy donors at the age of 29-33 (male, Caucasian). The hBMSC were expanded in $\alpha$-MEM containing $10 \%$ fetal calf serum (FCS), $100 \mathrm{U} /$ $\mathrm{mL}$ penicillin and $100 \mu \mathrm{g} / \mathrm{mL}$ streptomycin (Pen/Strep) and $2 \mathrm{mM}$ L-glutamine (all from Biochrom, Germany). The use of hBMSC for the experiments was approved by the ethics commission of the Technische Universität Dresden. For the experiments, hBMSC in passage 4-5 were used. Human umbilical vein endothelial cells (HUVEC; Promocell, Germany) were cultivated in Endothelial Cell Growth Medium (Promocell). Cells of passage 4-6 were used for the experiments.

\section{Cultivation and osteogenic differentiation of $h B M S C$}

Prior to cell seeding, scaffolds $(\mathrm{d}=6 \mathrm{~mm}, \mathrm{~h}=3 \mathrm{~mm})$ were pre-incubated in cell culture medium $(\alpha$-MEM) for $24 \mathrm{~h}$, then soaked dry by sterile filter paper and seeded by dropping $35 \mu \mathrm{L}$ of cell suspension containing $5 \times 10^{4}$ hBMSC on top of each scaffold. For initial adherence, the seeded scaffolds were incubated for 20 min under cell culture conditions before additional $500 \mu \mathrm{L}$ cell culture medium was added carefully. Stimulation of osteogenic differentiation was started one day after seeding by adding osteogenic supplements (+OS) to the medium $\left(10^{-8} \mathrm{M}\right.$ dexamethasone, $0.05 \mathrm{mM}$ ascorbic acid 2-phosphate, $5 \mathrm{mM} \beta$-glycerophosphate; all from Sigma-Aldrich). The experiment was performed three times, each run was conducted with hBMSC obtained from one of the three donors.

\section{Co-cultivation of HUVEC and hBMSC for in vitro angiogenesis}

Co-cultures of HUVEC and hBMSC (one donor) were seeded onto the surface of the scaffolds $(d=6 \mathrm{~mm}$, $\mathrm{h}=3 \mathrm{~mm}$ ) and cultivated in the presence of VEGF (rhVEGF-A ${ }_{165}$; Biomol, Hamburg, Germany) - either added to the medium (20 ng VEGF/mL) or loaded onto the scaffolds (60 ng VEGF/scaffold). For VEGF loading, the scaffolds were wetted with $60 \mathrm{ng}$ VEGF in phosphate buffered saline (PBS; Life technologies, Germany). After overnight incubation under cell culture conditions, scaffolds were rinsed once with Endothelial Cell Basal Medium (Promocell) and shortly dipped on a filter paper to remove excess liquid prior to cell seeding. A 1:1 mixture of $\alpha$-MEM containing $10 \%$ FCS and Endothelial Cell Growth Medium, with Pen/Strep and osteogenic supplements (+OS), was used as co-culture medium. Scaffolds were seeded with $35 \mu \mathrm{L}$ of a cell suspension containing $1.25 \times 10^{4} \mathrm{HUVEC}$ and $5 \times 10^{4} \mathrm{hBMSC}$ (ratio $1: 4)$ and incubated under cell culture conditions for $30 \mathrm{~min}$ before $500 \mu \mathrm{L}$ co-culture medium was added.

\section{Analysis of cell-seeded scaffolds \\ MTT-staining}

HBMSC-seeded scaffolds were incubated for $4 \mathrm{~h}$ in cell culture medium containing $1.2 \mathrm{mM} 3$-(4.5-dimethylthiazol2-yl)-2.5-diphenyltetrazolium bromide (MTT; SigmaAldrich) to stain viable cells dark blue. The scaffolds were cut longitudinally into two halves and imaged by stereo light microscopy (Leica M205C).

\section{Biochemical analysis of LDH and ALP activity}

After 1, 14 and $28 \mathrm{~d}$ of culture cell-seeded scaffolds were rinsed twice with PBS and frozen at $-80^{\circ} \mathrm{C}$ until analysis. After thawing, cells were lysed in $1 \%$ Triton X-100/PBS (Sigma-Aldrich) for $50 \mathrm{~min}$ on ice, supported by $10 \mathrm{~min}$ ultrasonic treatment. Cytosolic lactate dehydrogenase (LDH) activity was measured using the CytoTox $96^{\circledR}$ Non-Radioactive Cytotoxicity Assay (Promega, USA). The absorbance was measured at $492 \mathrm{~nm}$ and correlated to the cell number by using a calibration line. The same lysates were used to determine the specific alkaline phosphatase (ALP) activity by incubating an aliquot with ALP reaction buffer $(1 \mathrm{mg} / \mathrm{mL}$ p-nitrophenyl phosphate (Sigma, USA), 0.1 M diethanolamine, $1 \%$ Triton X-100 (pH 9.8), $1 \mathrm{mM} \mathrm{MgCl}_{2}$ ) for $30 \mathrm{~min}$ at $37{ }^{\circ} \mathrm{C}$. After stopping the enzymatic reaction by adding $1 \mathrm{M} \mathrm{NaOH}$, the absorbance were measured at $405 \mathrm{~nm}$ and correlated to a $\mathrm{pNp}$ ( $\mathrm{p}$-nitrophenol) calibration line and the according cell number to determine the specific ALP activity.

\section{Reverse Transcriptase PCR (RT-PCR)}

For RNA isolation hBMSC of one donor were used to seed five scaffolds per time point and scaffold variant. Lysates from those five scaffolds were than pooled for further RNA extraction with the peqGOLD Micro Spin Total RNA Kit (Peqlab, Germany). 100 ng of total RNA were reverse transcribed into cDNA in a $20 \mu \mathrm{L}$ reaction mixture 
containing $200 \mathrm{U}$ of Superscript II Reverse Transcriptase, $0.5 \mathrm{mM}$ dNTPs, $40 \mathrm{U}$ of RNase inhibitor RNase OUT (all Life Technologies) and $12.5 \mathrm{ng} / \mu \mathrm{L}$ random hexamers (Eurofins MWG Operon, Germany). Reaction mixtures containing $1 \mu \mathrm{L}$ cDNA mixed with specific primer pairs (1 $\mu \mathrm{M}$ of each primer; Eurofins MWG Operon), 1.5 U HotTaq-Polymerase (Peqlab), $0.2 \mathrm{mM}$ dNTPs and $1.5 \mathrm{mM}$ $\mathrm{MgCl}_{2}$ were used for amplification in PCR to detect transcripts of RunX2, ALP, Col1, OC and BSPII; GAPDH was used as reference gene (Primer details are summarised in Table 1). PCR products were visualised in $2 \%$ agarose gels (Ultra Pure ${ }^{\mathrm{TM}}$ Agarose, Life Technologies) stained with Gel Red (Biotium, USA); intensities of the DNA bands were analysed by ImageJ $1.44 p$ (NIH, USA). In order to express specific gene expression, the signal intensities of the osteogenic marker transcripts were related to those of the respective GAPDH transcripts.

\section{Immunofluorescence staining and imaging}

For immunofluorescence staining of co-cultures, cellseeded scaffolds were fixed with $3.7 \%$ formaldehyde in PBS for $30 \mathrm{~min}$, cut in longitudinal direction with a razor blade and fixed again for additional $5 \mathrm{~min}$. Then the scaffolds were incubated in $3 \%$ goat serum (SigmaAldrich) for $30 \mathrm{~min}$ to minimise unspecific staining followed by incubation with the primary antibody against CD31 (mouse anti-human; DAKO, Germany) for $1 \mathrm{~h}$. In a second step the secondary anti-mouse antibody labelled with either Alexa Fluor ${ }^{\circledR} 546$ or Alexa Fluor ${ }^{\circledR} 488$ (Life technologies) was added together with Hoechst 3342 (Life Technologies) for nuclei staining and incubated in the dark for $30 \mathrm{~min}$. In case of additional actin staining, Alexa Fluor ${ }^{\circledR} 546$ phalloidin (Thermo Fischer Scientific, USA) was added to the second staining solution. Confocal laser scanning microscopy was performed using a cLSM 510 (Carl Zeiss Microscopy GmbH, Germany), located in the Core Facility Cellular Imaging (CFCI) of Technische Universität Dresden. Images were processed with
ZEN2012 (confocal images, Carl Zeiss) and ImageJ 1.48t (Wayne Rasband, NIH, USA).

\section{Statistical analysis}

All results are shown as mean \pm standard deviation (SD). For comparison of two groups with equal variances, a student's $t$-test was performed while for multiple parametric groups, a one-way ANOVA test was run by using the software Origin 8.5.0G (OriginLab, Northampton, MA). Significant differences were assumed at $p \leq 0.05$.

\section{Results}

\section{Scaffold characterisation}

Influence of heparin on formation of mineralised collagen In order to investigate the influence of heparin on HA crystallisation during collagen fibril reassembly, composition and nanostructure of heparin-free scaffolds (0) were compared to in situ-modified scaffolds (I-150). The composition of mineralised collagen was examined by FT-IR (Fig. 1A). Both variants showed similar spectra with the characteristic peaks of the phosphate bands in HA: 607 and $561 \mathrm{~cm}^{-1}$ (O-P-O asymmetric and symmetric stretching mode), $961 \mathrm{~cm}^{-1}$ (P-O symmetric stretching mode) and $1027 \mathrm{~cm}^{-1}$ (P-O antisymmetric stretching mode) (Bradt et al., 1999; Hoyer et al., 2012). These results revealed that the presence of heparin does not affect HA formation. In order to investigate if heparin influences the formation of HA crystals with respect to morphology, distribution or size, the nanostructure of mineralised collagen scaffolds was examined by TEM (Fig. 1B). In both cases, 0 and I-150, the HA crystals appeared as dark needle- or plateletlike objects and seemed to be primarily aligned along the assumed collagen fibrils. The reconstituted collagen fibrils were not directly visible due to their low electron density and because no heavy metal salt was used for staining. Nevertheless, when comparing the TEM images with the

Table 1. Primers for RT-PCR.

\begin{tabular}{|c|c|c|c|c|}
\hline Marker & \multicolumn{2}{|c|}{ Primer sequences } & $\begin{array}{l}\text { T annealing } \\
\left({ }^{\circ} \mathrm{C}\right)\end{array}$ & $\begin{array}{l}\text { Amplicon size } \\
\text { (bp) }\end{array}$ \\
\hline \multirow{2}{*}{$\begin{array}{l}\text { Glyceraldehyde-3-phosphate } \\
\text { dehydrogenase (GAPDH) }\end{array}$} & for & 5'-GGT GAA GGT CGG AGT CAA CGG-3' & \multirow{2}{*}{62} & \multirow{2}{*}{520} \\
\hline & rev & 5'-GGT CAT GAG TCC TTC CAC GAT-3' & & \\
\hline \multirow{2}{*}{$\begin{array}{l}\text { Runt-related transcription } \\
\text { factor } 2 \text { (RunX2) }\end{array}$} & for & 5'-GGT AAC GAT GAA AAT TAT TCT GCT G-3' & \multirow{2}{*}{58} & \multirow{2}{*}{201} \\
\hline & rev & 5'-CCG AGG TCC ATC TAC TGT AAC-3' & & \\
\hline \multirow{2}{*}{ Alkaline phosphatase (ALP) } & for & 5'-ACC ATT CCC ACG TCT TCA CAT TTG-3' & \multirow{2}{*}{61} & \multirow{2}{*}{162} \\
\hline & rev & 5'-ATT CTC TCG TTC ACC GCC CAC-3' & & \\
\hline \multirow{2}{*}{ Collagen 1 (Col 1) } & for & 5'-GGA TGA GGA GAC TGG CAA C-3' & \multirow{2}{*}{59} & \multirow{2}{*}{331} \\
\hline & rev & 5'-GAA GAA GAA ATG GCA AAG AGA AAG-3' & & \\
\hline \multirow{2}{*}{ Osteocalcin (OC) } & for & 5'-CAA AGG TGC AGC CTT TGT GTC-3' & \multirow{2}{*}{60} & \multirow{2}{*}{177} \\
\hline & rev & 5'-TCA CAG TCC GGA TTG AGC TCA-3' & & \\
\hline \multirow{2}{*}{ Bone sialoprotein II (BSP II) } & for & 5'-AAT GAA AAC GAA GAA AGC GAA G-3' & \multirow{2}{*}{56} & \multirow{2}{*}{450} \\
\hline & rev & 5'-ATC ATA GCC ATC GTA GCC TTG T-3' & & \\
\hline
\end{tabular}


SEM micrographs the elongated, light areas in Fig. 1B represent most likely the collagen fibrils. The nanocrystals appeared in both samples similar in morphology and size, with about $50 \mathrm{~nm}$ in length.

Influence of heparin modification on mechanical properties The mechanical properties of 0, I-150 and P-150 scaffolds were characterised by measuring the compressive modulus and the compressive stress until $50 \%$ compression (Fig. 2A). Compared to unmodified scaffolds, the compressive stress of post-modified scaffolds decreased from $27.7 \pm 1.1 \mathrm{kPa}$ to $21.8 \pm 1.2 \mathrm{kPa}$ at $50 \%$ compression; the compressive modulus was significantly reduced (Fig.
2B). In contrast, compression properties of in situ-modified scaffolds appeared to be similar to those of unmodified scaffolds.

Heparin-modified scaffolds under cell culture conditions Heparin content of the scaffolds was determined before and after $28 \mathrm{~d}$ of incubation in cell culture medium. As already observed previously (Knaack et al., 2014), heparin was successfully incorporated with both methods. Post scaffolds bound about $95 \%$ of the exposed heparin whilst in situ scaffolds incorporated heparin less efficiently $(80 \%$ in case of I-150). After $28 \mathrm{~d}$, heparin content of all scaffold variants was decreased: approx. $60 \%$ of the heparin

A
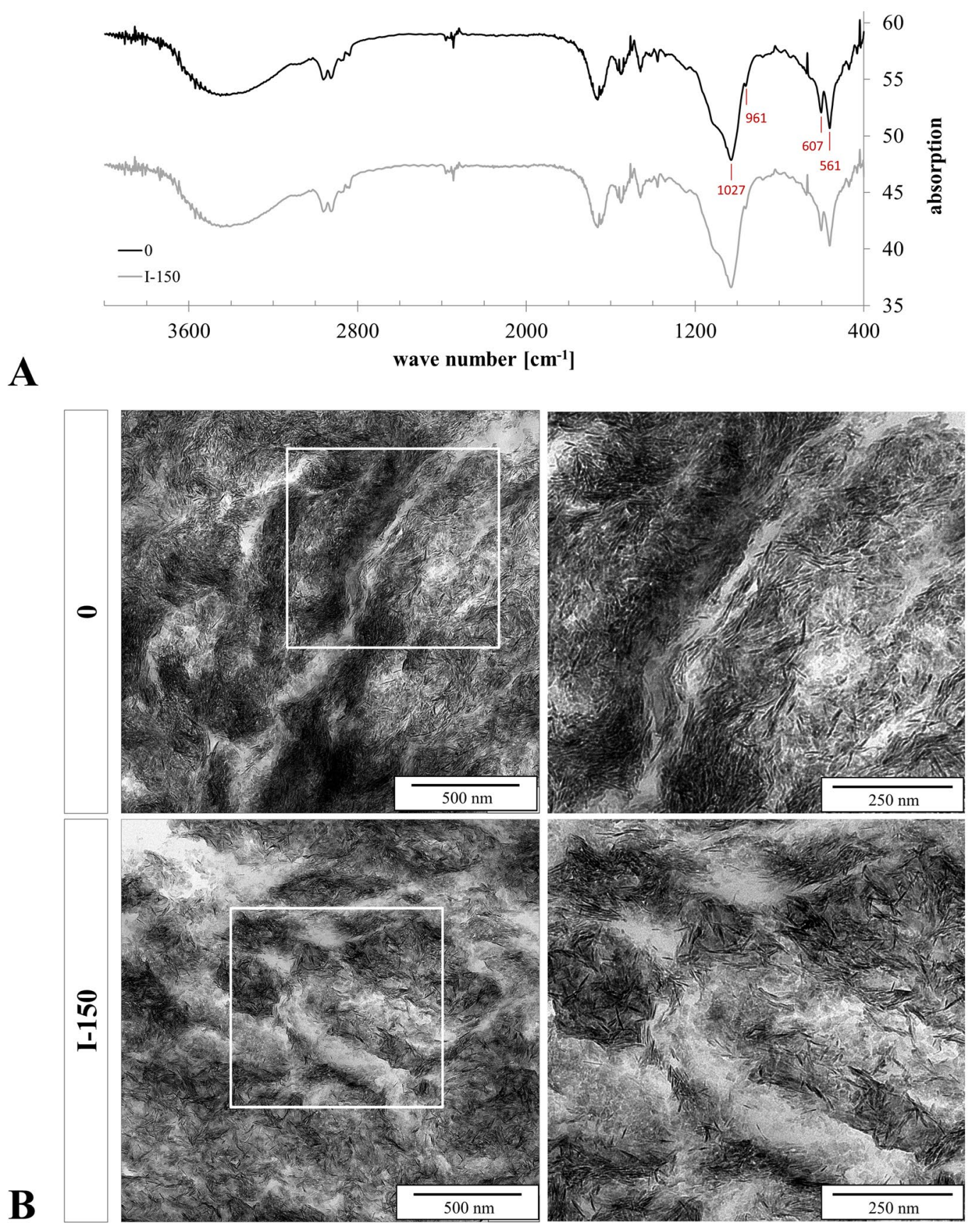

Fig. 1. Formation of mineralised collagen in the presence of heparin. (A) FT-IR spectra (B) TEM images of ultrathin, non-stained scaffold sections. (heparin-free (0); heparin-modified scaffolds prepared after in situ- (I) protocol with $150 \mathrm{mg}$ heparin/g collagen). 
amount used for modification was still detected if 75 and $150 \mathrm{mg} / \mathrm{g}$ collagen were used; in case of modification with $30 \mathrm{mg} / \mathrm{g}$ collagen, around $80 \%$ remained (Fig. 3A,B). Post-modified scaffolds tended to lose a larger amount of heparin; however, this was not significant (Fig. 3C). Scaffolds with greater heparin content released significantly more heparin. For example, P-150 lost about $36 \%$ of bound heparin, whilst P-30 released only $16 \%$ (Fig. 3D).

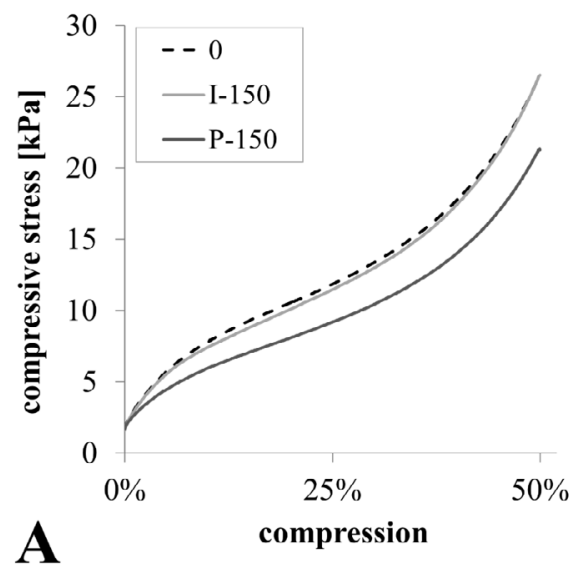

Proliferation and osteogenic differentiation of hBMSC cultured on heparin-modified mineralised collagen scaffolds

Viability, proliferation and distribution of hBMSC within the scaffolds

After seeding with hBMSC cell viability and colonisation of the scaffolds were visualised by MTT staining at different time points of cultivation (Fig. 4A). At day 1, the seeded cells were located predominantly in the upper $1 \mathrm{~mm}$ of the scaffolds, while after 14 and $28 \mathrm{~d}$ the whole scaffolds were colonised, which indicates their migration throughout

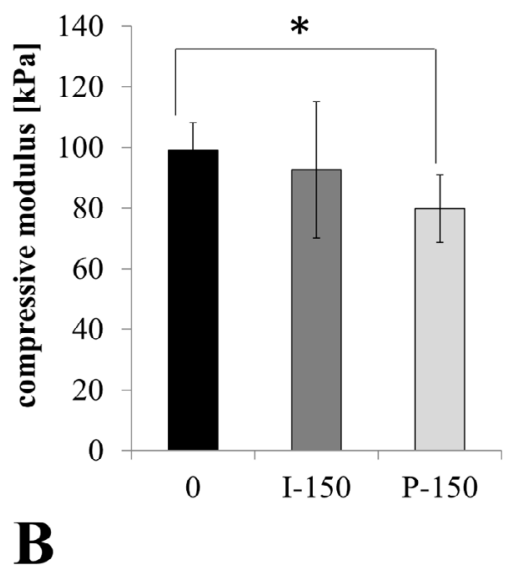

Fig. 2. Mechanical properties of mineralised collagen scaffolds modified with heparin. (A) Representative compressive stress-strain curves (until $50 \%$ deformation); (B) compressive modulus calculated in the range of 0-2 \% of compression (mean $\pm \mathrm{SD} ; n=5 ; * p<0.05$ ). (heparin-free (0); heparin-modified scaffolds prepared after in situ- (I) and post- $(\mathrm{P})$ protocol with $150 \mathrm{mg}$ heparin/g collagen).
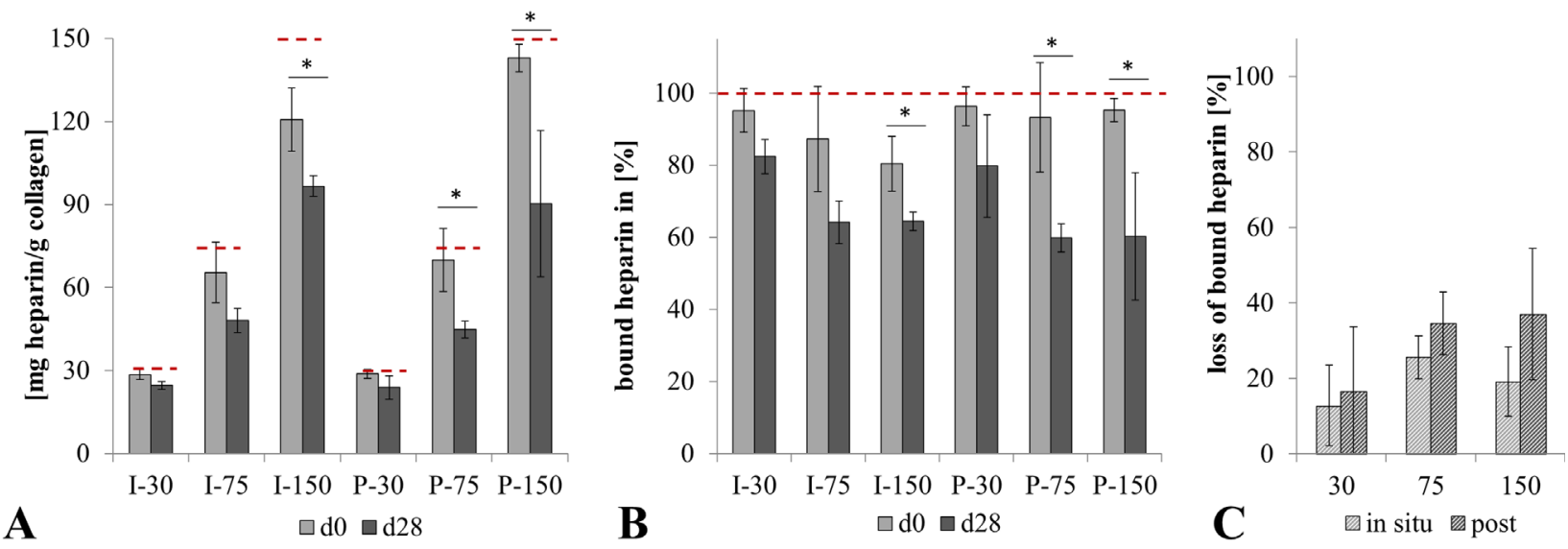

\begin{tabular}{|c|c|c|c|c|}
\hline \multicolumn{2}{|l|}{ [mg heparin/g collagen] } & 30 & 75 & 150 \\
\hline \multirow{2}{*}{$\begin{array}{c}\text { released heparin/ scaffold during } 28 \text { days of } \\
\text { cultivation } \\
{[\mu \mathrm{g}]}\end{array}$} & in situ & $18.24 \pm 15.27$ & $83.74 \pm 18.71$ & $115.36 \pm 55.74$ \\
\hline & post & $23.96 \pm 24.67$ & $120.83 \pm 28.99$ & $264.04 \pm 124.69$ \\
\hline
\end{tabular}

Fig. 3. Heparin-content of in situ- (I) and post- (P) modified scaffolds before and after $28 \mathrm{~d}$ of incubation in cell culture medium with regular changes of medium every third day. (A) Amount of heparin bound to the scaffolds and (B) as percentage of the respective amount applied for modification; (C) loss of heparin after $28 \mathrm{~d}$ of incubation as percentage of the amount of heparin bound at day 0; (D) calculated amount of released heparin per scaffold after $28 \mathrm{~d}$ of incubation. Quantification via DMMB-Assay (mean $\pm \mathrm{SD} ; n=3 ;{ }^{*} p<0.05$ ). 

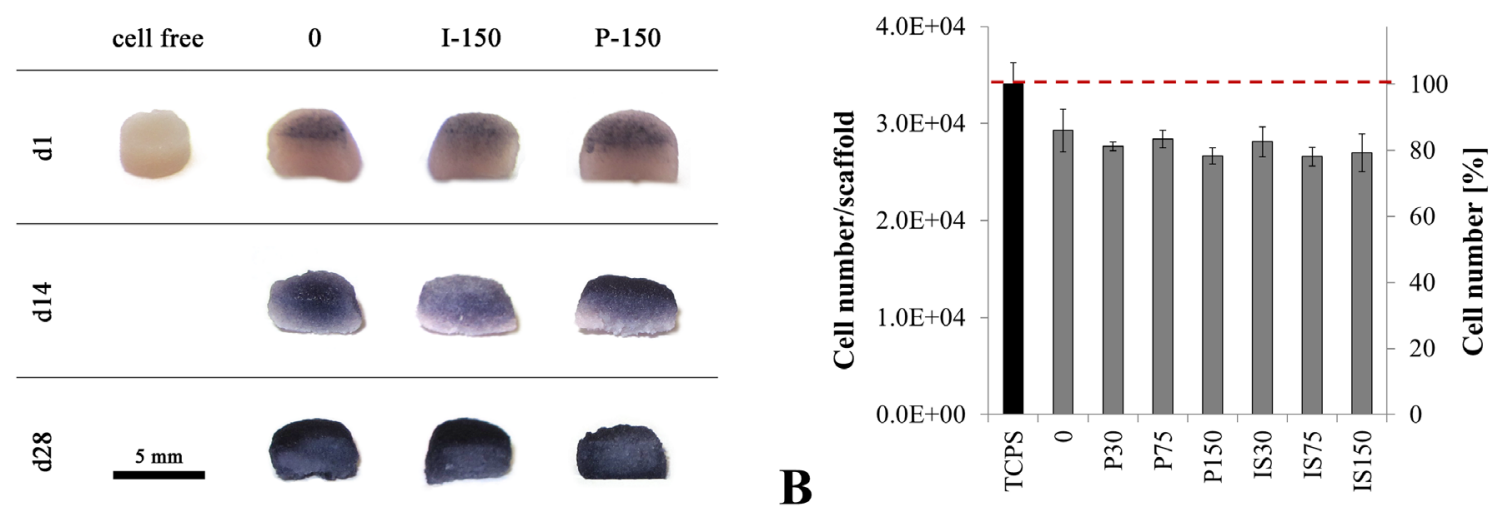

Fig. 4. Proliferation of hBMSC on mineralised collagen scaffolds with and without heparin-modification. (A) Viability and distribution of hBMSC visualised by MTT staining (non-induced hBMSC representatively). To demonstrate cell colonisation also of the inner scaffold regions, the scaffolds were cut longitudinally into two halves before imaging. (B) Cell recovery $24 \mathrm{~h}$ after seeding of $4 \times 10^{4}$ cells onto the scaffolds, determined by quantification of LDH activity $(n=3, \pm \mathrm{SD})$. (heparin-free (0); heparin-modified scaffolds prepared after in situ- (I) and post- (P) protocol with 30,75 and $150 \mathrm{mg}$ heparin/g collagen).

\section{in situ (I)}
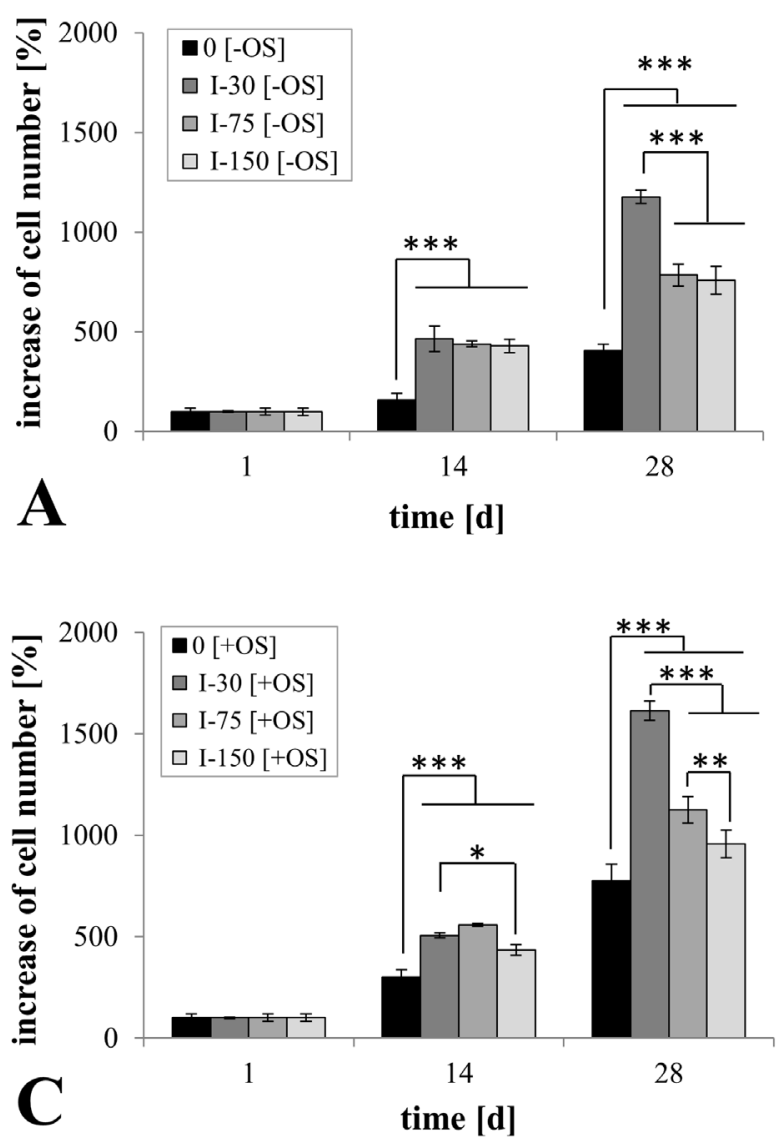

post (P)
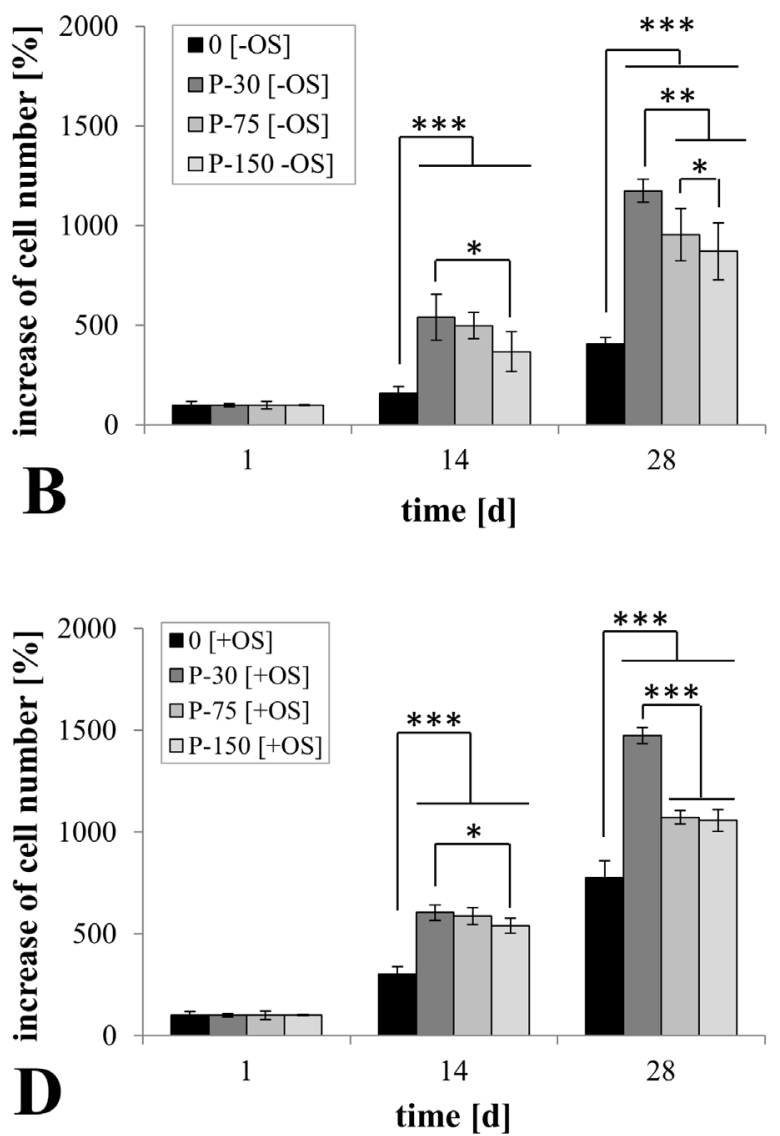

Fig. 5. Proliferation of hBMSC cultured on mineralised collagen scaffolds modified with heparin after in situ- (I) $(\mathbf{A}, \mathbf{C})$ and post- $(\mathbf{P})(\mathbf{B}, \mathbf{D})$ protocol in comparison to heparin-free scaffolds $(0)$. $(\mathbf{A}, \mathbf{B})$ hBMSC cultured without osteogenic supplements [-OS]; (C,D) hBMSC cultured with osteogenic supplements [+OS]. Cell numbers determined by quantification of LDH activity and normalised to values of day $1(n=3, \pm \mathrm{SD}, * p<0.05, * * p<0.005$, $* * * p<0.0005)$. 
the interconnected porous network - no obvious differences between scaffold variants and culture conditions ( \pm OS) were visible.

The number of viable cells in the scaffolds was quantified using the LDH activity in the lysates. Cell numbers determined $24 \mathrm{~h}$ after seeding revealed a seeding efficiency of about $80 \%$ for all scaffold variants - independent from heparin-modification (Fig. 4B).

During cultivation with and without osteogenic supplements over $28 \mathrm{~d}$, the cells proliferated on all scaffold variants (Fig. 5). Generally, cell numbers were significantly higher on scaffolds modified with heparin. After $28 \mathrm{~d}$, cellseeded scaffolds incubated without osteogenic supplements showed a 4-fold increase of cell number on unmodified scaffolds, compared to a 12-fold raise on I-30 and P-30 scaffolds (Fig. 5A,B). The proliferation rates were not affected by the modification method. Similar effects were seen for osteogenically induced hBMSC, with an 8-fold increase of cell number on unmodified and a 16-fold raise on I-30 and P-30 scaffolds (Fig. 5C,D). The positive effect of heparin declines with increasing concentrations; however, scaffolds modified with $150 \mathrm{mg}$ heparin/g collagen (I-150, P-150) still showed considerably higher cell numbers compared to heparin-free scaffolds.
Osteogenic differentiation of hBMSC within the scaffolds The influence of heparin modification of mineralised collagen scaffolds on the osteogenic differentiation of hBMSC was first determined by measuring the ALP activity (Fig. 6). Osteogenically induced hBMSC exhibited significantly higher values when cultivated on scaffolds modified with heparin; the ALP activity appeared to increase in correlation with the amount of incorporated heparin - even in cells not osteogenically induced. This result was confirmed by repetition of the experiment with hBMSC of two other donors. In addition, the osteogenic differentiation was further investigated on transcript level by seeding heparin-modified scaffolds with hBMSC of one donor and determining the expression of additional osteogenic markers by semi-quantitative RT-PCR (Fig. 7). The specific transcription factor RunX2 was expressed from day 1; the expression level increased over time for all variants and showed strongest expression on scaffolds with highest heparin concentrations (I-150, P-150) at day 28 of culture with osteogenic supplements. Consistent with ALP activity measurements, ALP expression was upregulated in cells cultured on heparin-modified scaffolds in a concentration-dependent manner. This trend was also observed for undifferentiated hBMSC. Col I

\section{in situ (I)}
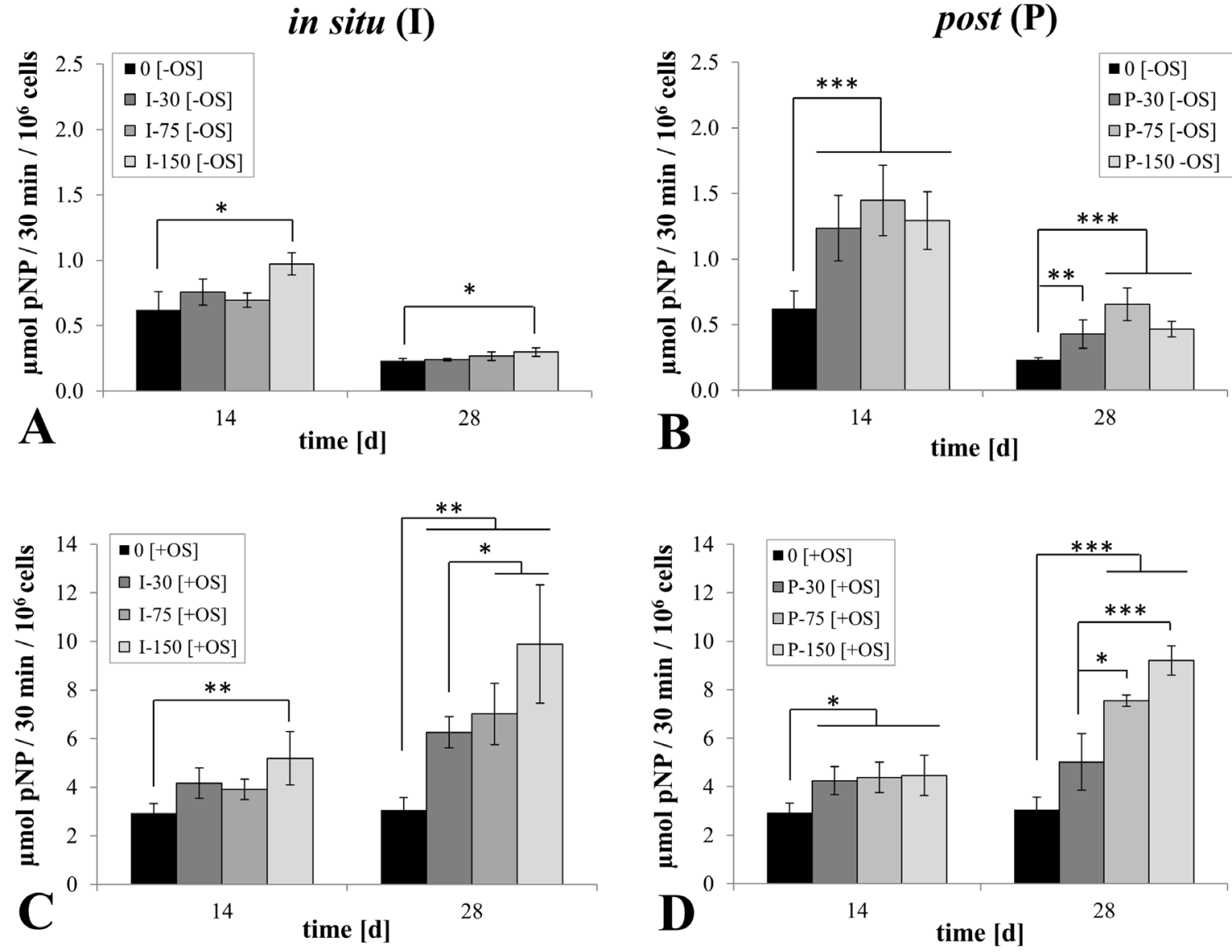

Fig. 6. Specific ALP activity of hBMSC cultured on mineralised collagen scaffolds modified with heparin after in situ- (I) $(\mathbf{A}, \mathbf{C})$ and post- (P) $(\mathbf{B}, \mathbf{D})$ protocol in comparison to heparin-free scaffolds $(0)$. $(\mathbf{A}, \mathbf{B})$ hBMSC cultured without osteogenic supplements [-OS]; (C,D) hBMSC cultured with osteogenic supplements [+OS]. ALP activity was determined from cell lysates and correlated to the respective cell number $\left(n=3\right.$, mean $\pm \mathrm{SD},{ }^{*} p \leq 0.05, * * p \leq 0.005$, $* * * p \leq 0.0005)$. Different scales of $\mathrm{y}$-axes are used for non-induced and induced cells. 
showed increased expression after $28 \mathrm{~d}$ of incubation with osteogenic supplements on all scaffolds variants. However, OC expression tended to decrease with the heparin-concentration in the scaffolds and expression of BSP II was only detectable after $28 \mathrm{~d}$ of incubation on unmodified scaffolds and on scaffolds with the lowest amount of heparin (I-30, P-30).
In vitro angiogenesis - co-cultures of HUVEC and hBMSC on heparin-modified mineralised collagen scaffolds

Modifying the scaffolds with heparin allows functionalisation with specific growth factors in order to actively stimulate desired cell functions - such as angiogenesis. In this study, functionalisation with VEGF was conducted to induce angiogenesis: formation of
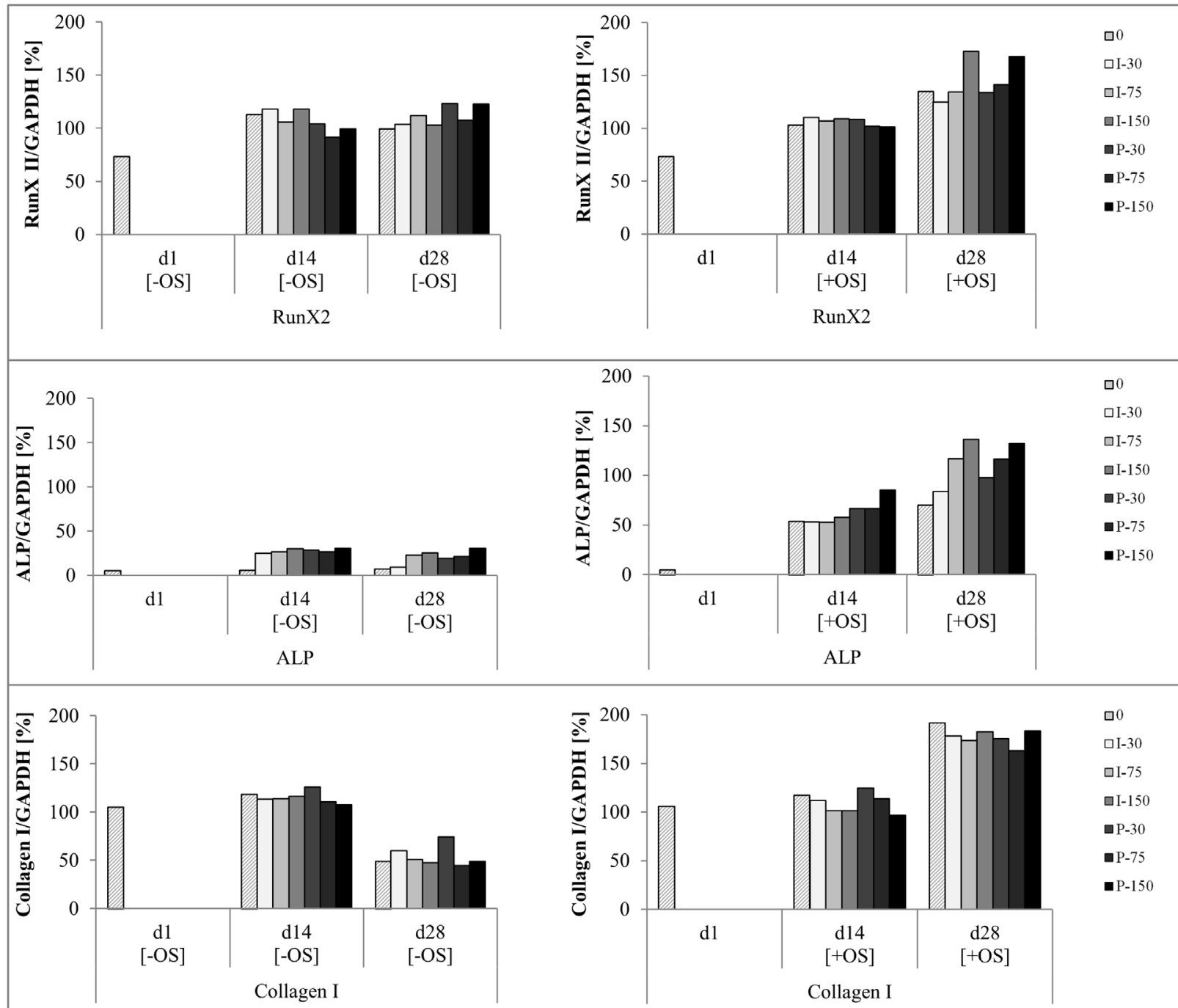

$\square 0$

$\square \mathrm{I}-30$

$\square \mathrm{I}-75$

$\square \mathrm{I}-150$

口P-30

-P-75

- $\mathrm{P}-150$

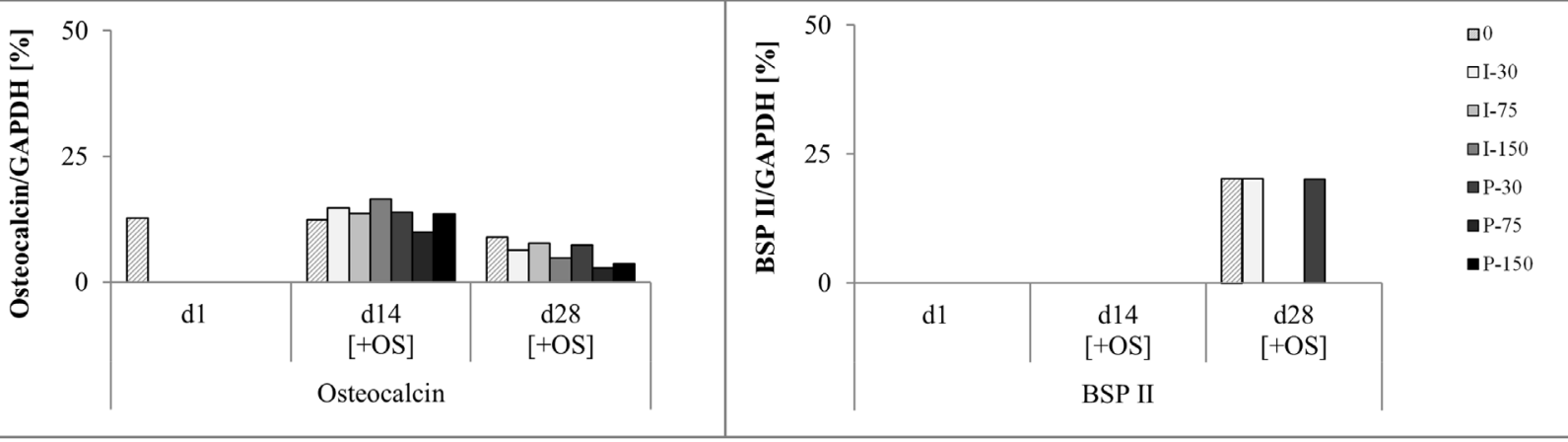

Fig. 7. Influence of heparin modification of mineralised collagen scaffolds on expression levels of osteogenic markers. PCR products were visualised in agarose gels; the intensities of the resulting DNA bands were analysed by Image J 1.49 and related to the intensity of GAPDH-bands. Since RNA of the 5 parallel samples was pooled before PCR analysis, no standard deviations are given (heparin-free (0); heparin-modified scaffolds prepared after in situ- (I) and post- (P) protocol). 
prevascular structures in the form of vascular endothelial tubules was investigated by applying a HUVEC/hBMSC co-culture. At first VEGF was added directly to the medium (20 ng VEGF/mL) in order to investigate, whether tubular structures are formed inside the mineralised collagen scaffolds, when VEGF is available in sufficient concentrations. After $14 \mathrm{~d}$ of incubation CLSM images showed a clear prevascular network consisting of many cells aligned along the tubule structure, which was stained for the endothelial specific protein CD31 (PECAM-1) (Fig. 8A). CD31-positive structures visible in the section indicated the ability of sprouting through the interconnected pore system of the scaffolds. Even without additional factors tubule formation occurred, which was, however, more pronounced in the presence of VEGF (Fig. 8B). With rising heparin concentrations in the scaffolds, the tubule density was reduced (Fig. 8C). Thus, only unmodified scaffolds and scaffolds with the lowest heparin content (I-30; P-30) were applied for direct functionalisation: The scaffolds were loaded with $60 \mathrm{ng}$ VEGF/scaffold, seeded with HUVEC and hBMSC and incubated in co-culture medium without further VEGF supplementation (Fig. 9). After $14 \mathrm{~d}$, the strongest formation of prevascular structures was observed on heparin-free scaffolds with massive sprouting and branching on the scaffolds surface. Analysis of scaffold sections revealed that sprouting occurred up to a depth of approximately $750 \mu \mathrm{m}$. In comparison, the tubular structures on heparin-modified scaffolds appeared less pronounced with only rare branching and sprouting (400-500 $\mu \mathrm{m}$ in depth). However, at day 28 the opposite effect appeared: while the prevascular network on the surface of heparin-free scaffolds showed degradation, the structures on heparin-containing scaffolds persisted.

\section{Discussion}

\section{Material properties}

Two approaches were applied for modification of mineralised collagen scaffolds with heparin: integration during material synthesis (in situ) or addition to the porous scaffolds after their fabrication (post). In case of the in situ-modification, heparin was already present during the process of collagen fibril formation and mineralisation. Based on our observations from FT-IR and TEM analyses, we can conclude that heparin did not affect the precipitation of HA crystals. Formation of nanocrystalline HA was also indicated by EDX analysis of in situ-modified samples (data not shown). Moreover, quantification of the mineral content gave similar values for I-150 and the heparin-
A
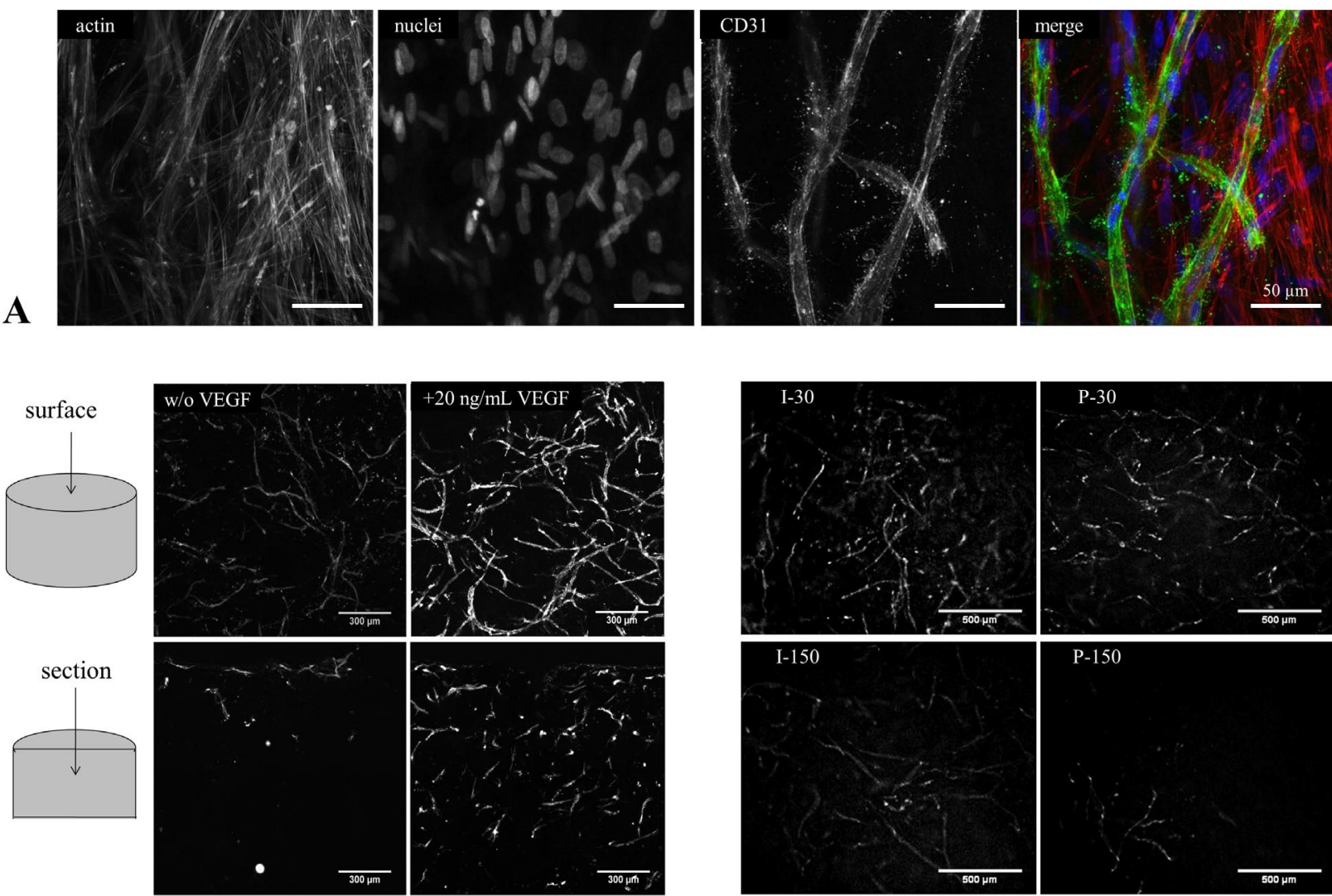

B
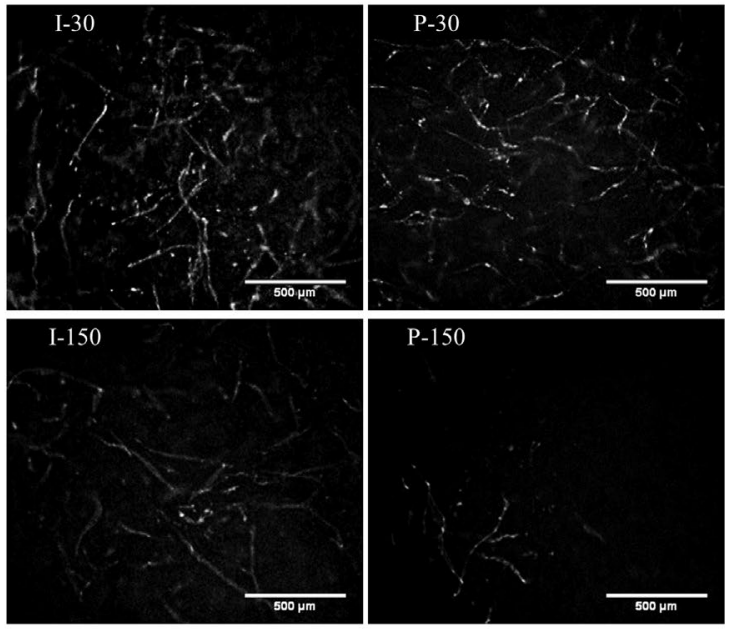

C

Fig. 8. Fluorescence microscopic images of tubular structures formed by a co-culture of osteogenically induced hBMSC and HUVEC within mineralised collagen scaffolds. The cell-seeded scaffolds were incubated for $14 \mathrm{~d}$ in co-culture medium containing $20 \mathrm{ng} / \mathrm{mL}$ VEGF. (A) Heparin-free scaffolds; fluorescence staining of nuclei (blue), actin cytoskeleton (red) and CD31 (green) to visualise tubular structures on the scaffold surface. (B) Heparin-free scaffolds; CD31 fluorescence staining of scaffold surface and section; cultivation with and without VEGF. (C) CD31 fluorescence staining of the scaffold surface; Scaffolds modified with 30 and $150 \mathrm{mg}$ heparin/g collagen after in situ (I) and post (P) protocol. 
free scaffold type confirming that heparin did not cause significant alteration of the mineralisation process (Knaack et al., 2014). After freeze-drying and EDC-crosslinking, in situ-modified scaffolds showed no changes in physical properties such as pore structure and size (Knaack et al., 2014) and mechanical behaviour. Interestingly, postmodified scaffolds showed slightly reduced compressive moduli, which might be caused by weakening of the porous scaffold structure through the additional freezing/ freeze-drying cycle.

Both approaches have been shown to be suitable to incorporate most of the heparin used for modification in the mineralised collagen matrix. However, consistent with our former results (Knaack et al., 2014), differences in the efficiency - reflecting the different mechanisms of integration - were observed with higher values for the post-samples, especially at higher heparin amounts.
Incubation of the heparin-modified samples under cell culture conditions over $28 \mathrm{~d}$ resulted in a moderate release of heparin that was more affected by the quantity of heparin than by the approach used for modification. Nevertheless, in situ-modification seems to result in a more stable heparin binding, probably caused by the direct interaction of heparin with collagen monomers and nascent fibrils during fibrillogenesis as discussed previously (Knaack et al., 2014) and due to the participation of carboxyl groups of heparin in the chemical crosslinking process (Murugesan et al., 2008). Our previous studies indicated that the EDC crosslinking of the in situ-samples does not affect the desired function of heparin: in comparison to the post-samples (where the heparin was added after EDC crosslinking), there were only marginal differences in the binding and release of VEGF (Knaack et al., 2014) and the adsorption of diverse model proteins (König et al., 2014).

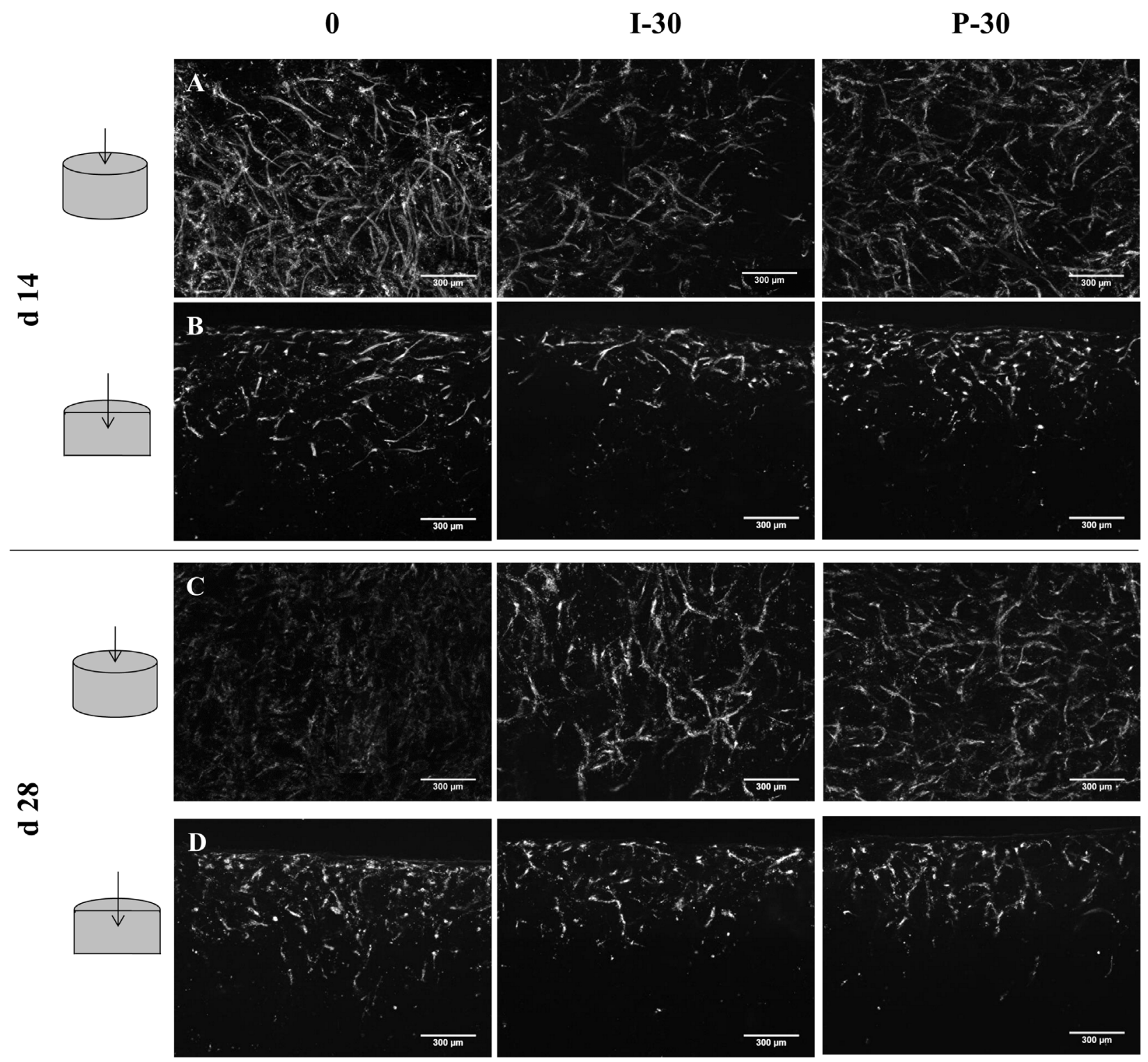

Fig. 9. Co-culture of osteogenically induced hBMSC and HUVEC on VEGF-functionalised scaffolds: microscopic images of tubular structures visualised by fluorescence staining of CD31. Heparin-free (0) and heparin-modified (I-30, P-30) scaffolds of mineralised collagen were loaded with $60 \mathrm{ng}$ VEGF; cell-seeded scaffolds were cultured for 14 and $28 \mathrm{~d}$ in co-culture medium. (A,C) scaffold surfaces, $(\mathbf{B}, \mathbf{D})$ cross sections through the scaffold centre (heparin-modified scaffolds prepared after in situ- (I) and post- (P) protocol with $30 \mathrm{mg}$ heparin/g collagen). 
In line are the observations of the cell culture experiments in the present study: the effects of the in situ- and the postsamples resemble each other.

\section{Cultivation of hBMSC on heparin-modified scaffolds}

In the cell culture experiments, heparin was present either in an immobilised state or - to a smaller amount - dissolved in the medium (the proportion released from the scaffold - as shown in Fig. 3). Immobilised heparin is able to enrich and stabilise signalling factors with heparin binding domains on the scaffold surface (Ma et al., 2015). FCS served as source for exogenous proteins, providing adhesion molecules as well as growth factors. Benoit et al. (2007) for example measured about $30 \mathrm{ng} / \mathrm{mL}$ fibronectin and $84 \mathrm{pg} / \mathrm{mL}$ bone morphogenetic protein II (BMP II) in cell culture medium containing $10 \% \mathrm{FCS}$. The high affinity of heparin to adhesion molecules like fibronectin and vitronectin facilitates not only a better cell attachment and proliferation (Uygun et al., 2009; Kim et al., 2013) but also promotes the differentiation of pre-osteoblastic cells through integrin mediated signal transduction (Mathews et al., 2012).

In our study, a promoting effect on seeding efficiencies due to enhanced binding of adhesion molecules, as described for heparin-modified biomaterials by others (Benoit and Anseth, 2005; Uygun et al., 2009; Kim et al., 2013), was most probably concealed by the porous scaffold physically capturing the cells. The proliferation of hBMSC, however, was significantly higher within heparin-modified scaffolds, which can be attributed to an enhanced binding of adhesion molecules as well as an interaction of heparin with growth factors like bFGF. Interestingly, the positive effect declined with rising heparin concentration. Increasing the heparin amount in the scaffolds had consequences, which could explain this observation: the number of potential binding sites within the scaffolds increased which may entail a stronger binding of factors with heparin-binding domains. Growth factors, which have to be soluble to bind their corresponding receptors, could therefore be absorbed by the matrix, making them inactive for cellular signal transmission. On the other hand, the amount of heparin in the medium, due to release from the scaffolds, increased too. A positive effect of heparin-complexation by stabilisation and protection from proteolytic inactivation has been described (e.g. Ma et al., 2015). Moreover, an enhanced heparin-mediated receptor-binding and therefore improved bioactivity have been reported, among others, for bFGF (Roghani et al., 1994) and VEGF (Ono et al., 1999). However, if the concentration of heparin in the medium is too high, the effect could be reversed by competitively inhibiting the specific interaction with the receptors at the cell surface, as demonstrated e.g. for bFGF (Fannon et al., 2000) and VEGF (Ono et al., 1999).

Another consequence of higher heparin concentrations was a concentration-dependent increase of ALP activity. A higher proportion of cells differentiating into the osteoblastic lineage could also have caused reduced cell proliferation (Bruder et al., 1994). In accordance with ALP activity, highest expression of ALP and the specific transcription factor RunX2 was detected on scaffolds with high heparin content confirming a promoting effect of the heparin modification on osteogenic differentiation. Determination of mineral deposition in the scaffolds is not possible as they contain HA. However, additional experiments on tissue culture polystyrene revealed that osteogenic stimulation of hBMSC in the presence of heparin $(30 \mu \mathrm{g} / \mathrm{mL})$ not only led to a 4-fold higher ALP activity but also to a 2.3-fold increased mineralisation (data not shown).

Although the genes of major bone matrix proteins like Col I, OC and BSP II are known to have DNA-binding sites for RunX2 and induction of their expression by RunX2 has been shown (Komori, 2006), our results indicated surprisingly no upregulation or even a decrease of matrix protein expression on heparin-modified scaffolds. This effect was most obvious in case of BSP II. Whereas existing data in the literature primarily show increased ALP expression and activity and mineralisation in response to heparin, the situation regarding the regulation of matrix protein expression is not clear: Hausser and Brenner (2004) described a concentrationdependent upregulation of OC by Saos- 2 cells. Mathews et al. (2014) found in hBMSC cultured on heparin-treated tissue culture plates an upregulated $\mathrm{OC}$ expression too, but no significant upregulation of Col I and BSP II expression. Recently, Simann et al. (2015) investigated the effect of heparin on osteogenic lineage commitment of hBMSC and found also no upregulation of OC, but concluded from their observations of ALP stimulation and enhanced mineralisation that heparin supported osteogenic differentiation.

\section{Influence of the heparin modification on in vitro angiogenesis within the scaffolds}

Previous work of our group demonstrated that the heparin modification of mineralised collagen scaffolds led to an almost linear release of VEGF (Knaack et al., 2014). Based on these findings, the present work intended to evaluate the potential of VEGF loaded onto the scaffolds to stimulate vascularisation - as a first step towards the envisaged in vivo application. In our co-culture system, human endothelial cells were cultivated together with osteogenically induced hBMSC in order to combine two cell types relevant for bone regeneration and facilitate the cellular crosstalk of bone and endothelial cells, which is known to promote the formation of prevascular networks by production of pro-angiogenic factors (Unger et al., 2015). Co-cultivation of both cell types resulted in the spontaneous formation of rather weak tubular structures, capable of sprouting into the porous scaffold. When exogenous VEGF was added to the medium, sprouting was more pronounced. The observation of a strong decline of CD31-positive structures with increasing heparin content can be most probably attributed to the interference of heparin immobilised in the matrix with cellular signal transmission by absorbing soluble factors as discussed above.

Grellier et al. (2009) have summarised the interaction of osteoblastic and endothelial cells by means of soluble factors - both cell types produce factors affecting growth and differentiation of each other. Endothelial cells on the one hand, produce among others BMP II and insulin-like 
growth factor (IGF) (Grellier et al., 2009). Osteoblasts, on the other hand, secrete sufficient quantities of VEGF to enhance survival and differentiation of endothelial cells (Kaigler et al., 2003), causing weak tubule formation on scaffolds without exogenous VEGF. All factors mentioned have heparin-binding domains and are therefore capable to interact with the heparin-modified scaffold matrix that in turn could modulate cellular reactions.

When VEGF was loaded onto the scaffolds, formation of prevascular structures was observed in both, heparinfree and heparin-modified (I-30; P-30) scaffolds. The observed differences in terms of tubule formation can be correlated with VEGF retention: after $14 \mathrm{~d}$, heparin-free scaffolds showed the densest and most defined prevascular structures; in comparison, both heparin-modified scaffold types exhibited a less pronounced tubular network. However, the prevascular network on heparin-modified scaffolds persisted with only slight degradation over $28 \mathrm{~d}$, while on heparin-free scaffolds the network on the scaffold surface was almost completely degraded. Referring to the release kinetics of VEGF previously published, heparinfree scaffolds released VEGF with an initial burst; after $7 \mathrm{~d}$, almost all loaded VEGF was released. In contrast, no initial burst but constant release of VEGF was detected for the heparin-modified scaffolds (Knaack et al., 2014). Presumably, the high initial concentration of VEGF from heparin-free scaffolds was beneficial to stimulate angiogenesis in the beginning, but insufficient VEGF supply at later time points led to degradation of the formed network as VEGF is required for stabilisation of immature vessels and survival of endothelial cells (Alon $\mathrm{T}$ et al., 1995; Gerber et al., 1998). The comparably low amount of VEGF released from scaffolds modified with $30 \mathrm{mg}$ heparin/g collagen was most probably responsible for the less pronounced but more persistent tubule formation in these scaffold types.

\section{Towards advanced tissue engineering concepts}

The data indicate that an initial burst release of VEGF is favourable for the onset of angiogenesis, while a sustained release from heparin-modified scaffolds led to a prolonged supply and therefore better maintenance of tubular structures. Towards the development of improved TE concepts, the combination of both, the initial burst release of larger amounts and the prolonged release of smaller doses of VEGF, could be able to significantly improve prevascular tubule formation and their persistence during long-term cultivation. The development of hydrogelbased depots for growth factors centrally integrated in the scaffolds is the aim of our ongoing work. Using such a strategy, sustained release of VEGF could be achieved from a heparin-modified depot in the centre of an otherwise heparin-free scaffold, which would initially set free a larger amount of the loaded VEGF within the first days. Moreover, a growth factor gradient formed within the scaffolds due to the release from the central depot might stimulate cell migration and vascularisation towards the scaffold centre.

In vivo, angiogenesis is a multi-factor process, which is regulated by an interplay of a large number of factors and cell types (Nillesen et al., 2007; Kirkpatrick et al.,
2011). Therefore, favourable approaches to induce and maintain the integrity of prevascular structures could be the functionalisation with synergistically acting factors such as VEGF and FGF (Nillesen et al., 2007) and/or angiogenin 1 (Zacchigna et al., 2007). By loading heparin-modified mineralised collagen scaffolds (P-75) with the growth factors BMP-2 and the chemokine stromal derived factor 1 alpha (SDF-1 $\alpha$ ), Zwingenberger et al. (2016) impressively demonstrated a sustained release of both factors over 6 weeks in vitro that enabled an improved bone healing in a murine critical size bone defect model. The data indicated that the osteoinductive potential of a low dose of BMP-2 was enhanced in the presence of SDF-1 $\alpha$. The study also showed that, even without further functionalisation new bone formation, osteoclast activity and vascularisation occurred in heparin-modified scaffolds in vivo.

Beside recombinant factors, cell-conditioned media with natural cocktails of signalling factors in physiological concentrations could also be promising to attract cells and induce the desired cellular response, such as the formation of integer prevascular structures as demonstrated for adipose tissue extracts (Sarkanen et al., 2012). Also, cell culture supernatants from hypoxia-treated hBMSC have been found to be highly potent for cell attraction and to contain a number of angiogenic factors (Gabrielyan et al., 2014). The effect of this cocktail on cell attraction and angiogenesis in mineralised collagen scaffolds is currently under investigation.

\section{Conclusion}

The results of this study indicate that modification of a biomimetic collagen/HA nanocomposite material with heparin allows for modulation of the cell response in key processes of bone regeneration. Proliferation and osteogenic differentiation of hBMSC cultured within heparin-modified scaffolds was increased, whereby the amount of heparin rather than the method used for modification had an impact on the cell fate; favouring proliferation at a small amount $(30 \mathrm{mg} / \mathrm{g}$ collagen) and osteogenic differentiation at larger amount $(150 \mathrm{mg} / \mathrm{g}$ collagen). Heparin modification did not affect basic material properties of the scaffolds. Therefore, the observed effects can be attributed to the presence of heparin either bound to the matrix or released into the medium. Using a co-culture of endothelial cells with osteogenically induced hBMSC, a prevascular network was formed that was more pronounced in the presence of exogenous VEGF. The interconnected pore system of the scaffolds favoured sprouting towards deeper scaffold areas, which is of great importance for vessel ingrowth. VEGF loading of the scaffolds influenced formation and stability of prevascular structures depending on the presence of heparin: Initial burst release of VEGF, observed for heparin-free scaffolds, seemed to favour tubule formation and sprouting, whereas prolonged release of small quantities of VEGF from the heparin-modified scaffolds seemed to stabilise the immature vessel-structures. In general, larger heparin amounts were found to be not suitable to support in vitro angiogenesis within the scaffolds. Due to the ability to adapt heparin 
concentration according to the patient's requirements, either hBMSC proliferation and angiogenesis (low heparin concentrations) or osteogenic differentiation (increasing heparin concentration) can be promoted. Therefore, this scaffold material could be of great interest for regenerative bone tissue engineering. Based on the results of the present study, novel TE concepts will be developed including the realisation of dual release kinetics (fast and slow release from one scaffold) and the application of growth factor cocktails from autologous sources.

\section{Acknowledgments}

The authors thank the German Research Foundation (DFG) for financial support. This study was performed as part of the Collaborative Research Centre/Transregio 79 (SFB/ TRR79; Subproject M4). We thank Ortrud Zieschang for excellent technical assistance and Dr. Armin Springer for sample preparation for TEM analysis. Furthermore, we are grateful to Syntacoll (Saal/Donau, Germany) for providing bovine collagen.

\section{References}

Alon T, Hemo I, Itin A, Pe’er J, Stone J, Keshet E (1995) Vascular endothelial growth factor acts as a survival factor for newly formed retinal vessels and has implications for retinopathy of prematurity. Nat Med 1: 1024-1028.

Benoit DSW, Anseth KS (2005) Heparin functionalized PEG gels that modulate protein adsorption for hMSC adhesion and differentiation. Acta Biomater 1: 461-470.

Benoit DSW, Durney AR, Anseth KS (2007) The effect of heparin-functionalized PEG hydrogels on threedimensional human mesenchymal stem cell osteogenic Differentiation, Biomaterials 28: 66-77.

Bernhardt A, Lode A, Mietrach C, Hempel U, Hanke T, Gelinsky M (2009) In vitro osteogenic potential of human bone marrow stromal cells cultivated in porous scaffolds from mineralized collagen. J Biomed Mater Res A 90A: 852-862.

Black CRM, Goriainov V, Gibbs D, Kanczler J, Tare RS, Oreffo ROC (2015) Bone tissue engineering. Curr Mol Biol Rep 1: 132-140.

Bradt J-H, Mertig M, Teresiak A, Pompe W (1999) Biomimetic mineralization of collagen by combined fibril assembly and calcium phosphate formation. Chem Mater 11: 2694-2701.

Brickman YG, Ford MD, Gallagher JT, Nurcombe V, Bartlett PF, Turnbull JE (1998) Structural modification of fibroblast growth factor-binding heparan sulfate at a determinative stage of neural development. J Biol Chem 273: 4350-4359.

Bruder SP, Fink DJ, Caplan AI (1994) Mesenchymal stem cells in bone development, bone repair, and skeletal regeneration therapy. J Cell Biochem 56: 283294.

Calarco A, Petillo O, Bosetti M, Torpedine A, Cannas M, Perrone L, Galderisi U, Melone MAB, Peluso G (2010) Controlled delivery of the heparan sulfate/FGF-2 complex by a polyelectrolyte scaffold promotes maximal hMSC proliferation and differentiation. J Cell Biochem 110: 903909.

Capila I, Linhardt RJ (2002) Heparin-proteinwechselwirkungen. Angew Chem 114: 426-450.

Chan BP, Leong KW (2008) Scaffolding in tissue engineering: general approaches and tissue-specific considerations. Eur Spine J 17: 467-479.

Chen L, He Z, Chen B, Yang M, Zhao Y, Sun W, Xiao Z, Zhang J, Dai J (2010) Loading of VEGF to the heparin cross-linked demineralized bone matrix improves vascularization of the scaffold. J Mater Sci Mater Med 21: 309-317.

Fannon M, Forsten K.E., Nugent M.A. (2000) Potentiation and inhibition of bFGF binding by heparin: a model for regulation of cellular response. Biochemistry 39: 1434-1445.

Gabrielyan A, Knaak S, Gelinsky M, Arnhold S, Rösen-Wolff A (2014) Hypoxia-conditioned media allows species-specific attraction of bone marrow stromal cells without need for recombinant proteins. BMC Vet Res 10: 56.

Gelinsky M, Welzel PB, Simon P, Bernhardt A, König U (2008) Porous three-dimensional scaffolds made of mineralised collagen: Preparation and properties of a biomimetic nanocomposite material for tissue engineering of bone. Chem Eng J 137: 84-96.

Gerber H-P, McMurtrey A, Kowalski J, Yan M, Keyt BA, Dixit V, Ferrara N (1998) Vascular endothelial growth factor regulates endothelial cell survival through the phosphatidylinositol 3'-Kinase/Akt signal transduction pathway requirement FOR Flk-1/KDR activation. J Biol Chem 273: 30336-30343.

Grellier M, Bordenave L, Amédée J (2009) Cell-tocell communication between osteogenic and endothelial lineages: implications for tissue engineering. Trends Biotechnol 27: 562-571.

Hausser H-J, Brenner RE (2004), Low doses and high doses of heparin have different effects on osteoblast-like Saos-2 cells in vitro. J Cell Biochem 91: 1062-1073.

Hoyer B, Bernhardt A, Heinemann S, Stachel I, Meyer M, Gelinsky M (2012) Biomimetically mineralized salmon collagen scaffolds for application in bone tissue engineering. Biomacromolecules 13: 1059-1066.

Kaigler D, Krebsbach PH, Polverini PJ, Mooney DJ (2003) Role of vascular endothelial growth factor in bone marrow stromal cell modulation of endothelial cells. Tissue Eng 9: 95-103.

Kanczler JM, Ginty PJ, Barry JJA, Clarke NMP, Howdle SM, Shakesheff KM, Oreffo ROC (2008) The effect of mesenchymal populations and vascular endothelial growth factor delivered from biodegradable polymer scaffolds on bone formation. Biomaterials 29: 18921900.

Kim M, Kim YH, Tae G (2013) Human mesenchymal stem cell culture on heparin-based hydrogels and the modulation of interactions by gel elasticity and heparin amount. Acta Biomater 9: 7833-7844.

Kirkpatrick CJ, Fuchs S, Unger RE (2011) Co-culture systems for vascularization - Learning from nature. Adv Drug Deliv Rev 63: 291-299. 
Knaack S, Lode A, Hoyer B, Rösen-Wolff A, Gabrielyan A, Roeder I, Gelinsky M (2014) Heparin modification of a biomimetic bone matrix for controlled release of VEGF: Heparin Modification of a Biomimetic Bone Matrix. J Biomed Mater Res A 102: 3500-3511.

Komori T (2006) Regulation of osteoblast differentiation by transcription factors. J Cell Biochem 99: 1233-1239.

König U, Lode A, Welzel PB, Ueda Y, Knaack S, Henß A, Hauswald A, Gelinsky M (2014) Heparinization of a biomimetic bone matrix: integration of heparin during matrix synthesis versus adsorptive post surface modification. J Mater Sci Mater Med 25: 607-621.

Kreuger J, Spillmann D, Li J, Lindahl U (2006) Interactions between heparan sulfate and proteins: the concept of specificity. J Cell Biol 174: 323-327.

Luong-Van E, Grøndahl L, Song S, Nurcombe V, Cool S (2007) The in vivo assessment of a novel scaffold containing heparan sulfate for tissue engineering with human mesenchymal stem cells. J Mol Histol 38: 459-468.

Ma C, Jing Y, Sun H, Liu X (2015) Hierarchical nanofibrous microspheres with controlled growth factor delivery for bone regeneration. Adv Healthc Mater 4: 2699-2708.

Mathews S, Bhonde R, Gupta PK, Totey S (2012) Extracellular matrix protein mediated regulation of the osteoblast differentiation of bone marrow derived human mesenchymal stem cells. Differentiation 84: 185-192.

Mathews S, Mathew SA, Gupta PK, Bhonde R, Totey S (2014) Glycosaminoglycans enhance osteoblast differentiation of bone marrow derived human mesenchymal stem cells: glycosaminoglycans enhanced osteoblast differentiation. J Tissue Eng Regen Med 8: 143-152.

Mishima Y, Lotz M (2008) Chemotaxis of human articular chondrocytes and mesenchymal stem cells. J Orthop Res 26: 1407-1412.

Müller G, Hanschke M (1996) Quantitative and qualitative analyses of proteoglycans in cartilage extracts by precipitation with 1,9-dimethylmethylene blue. Connect Tissue Res 33: 243-248.

Murugesan S, Xie J, Linhardt RJ (2008) Immobilization of heparin: approaches and applications. Curr Top Med Chem 8: 80 .

Nillesen STM, Geutjes PJ, Wismans R, Schalkwijk J, Daamen WF, van Kuppevelt TH (2007) Increased angiogenesis and blood vessel maturation in acellular collagen-heparin scaffolds containing both FGF2 and VEGF. Biomaterials 28: 1123-1131.

Ono K, Hattori H, Takeshita S, Kurita A, Ishihara M (1999) Structural features in heparin that interact with VEGF165 and modulate its biological activity. Glycobiology 9: 705-711.

Oyane A, Kim H-M, Furuya T, Kokubo T, Miyazaki T, Nakamura T (2003) Preparation and assessment of revised simulated body fluids. J Biomed Mater Res A 65A: 188195.

Pina S, Oliveira JM, Reis RL (2015) Natural-Based Nanocomposites for Bone Tissue Engineering and Regenerative Medicine: A Review. Adv Mater 27: 11431169.
Richardson TP, Peters MC, Ennett AB, Mooney DJ (2001) Polymeric system for dual growth factor delivery. Nat Biotechnol 19: 1029-1034.

Rodgers KD, San Antonio JD, Jacenko O (2008) Heparan sulfate proteoglycans: A GAGgle of skeletalhematopoietic regulators. Dev Dyn 237: 2622-2642.

Roghani M, Mansukhani A, Dell'Era P, Bellosta P, Basilico C, Rifkin DB, Moscatelli D (1994) Heparin increases the affinity of basic fibroblast growth factor for its receptor but is not required for binding. J Biol Chem 269: 3976-3984.

Rosso F, Giordano A, Barbarisi M, Barbarisi A (2004) From Cell-ECM interactions to tissue engineering. J Cell Physiol 199: 174-180.

Rouwkema J, Rivron NC, van Blitterswijk CA (2008) Vascularization in tissue engineering. Trends Biotechnol 26: 434-441.

Sanjurjo-Rodriguez C, Martínez-Sánchez AH, Hermida-Gómez T, Fuentes-Boquete I, Díaz-Prado S, Blanco FJ (2016) Differentiation of human mesenchymal stromal cells cultured on collagen sponges for cartilage repair. Histol Histopathol 31: 1221-1239.

Sarkanen J-R, Vuorenpää H, Huttala O, Mannerström B, Kuokkanen H, Miettinen S, Heinonen T, Ylikomi T (2012) Adipose stromal cell tubule network model provides a versatile tool for vascular research and tissue engineering. Cells Tissues Organs 196: 385-397.

Sasisekharan R, Venkataraman G (2000) Heparin and heparan sulfate: biosynthesis, structure and function. Curr Opin Chem Biol 4: 626-631.

Scholz M, Schleicher P, Eindorf T, Friedersdorff F, Gelinsky M, König U, Sewing A, Haas NP, Kandziora F (2010) Cages augmented with mineralized collagen and platelet-rich plasma as an osteoconductive/inductive combination for interbody fusion. Spine 35: 740-746.

Simann M, Schneider V, Le Blanc S, Dotterweich J, Zehe V, Krug M, Jakob F, Schilling T, Schütze N (2015) Heparin affects human bone marrow stromal cell fate: Promoting osteogenic and reducing adipogenic differentiation and conversion. Bone 78: 102-113.

Steffens GCM, Yao C, Prével P, Markowicz M, Schenck P, Noah EM, Pallua N (2004) Modulation of angiogenic potential of collagen matrices by covalent incorporation of heparin and loading with vascular endothelial growth factor. Tissue Eng 10: 1502-1509.

Szpalski C, Wetterau M, Barr J, Warren SM (2012) Bone tissue engineering: current strategies and techniques - Part I: Scaffolds. Tissue Eng Part B Rev 18: 246-257.

Thieme S, Ryser M, Gentsch M, Navratiel K, Brenner S, Stiehler M, Rölfing J, Gelinsky M, Rösen-Wolff A (2009) Stromal cell-derived factor- $1 \alpha$-directed chemoattraction of transiently CXCR4-overexpressing bone marrow stromal cells into functionalized three-dimensional biomimetic scaffolds. Tissue Eng Part C Methods 15: 687-696.

Unger RE, Dohle E, Kirkpatrick CJ (2015) Improving vascularization of engineered bone through the generation of pro-angiogenic effects in co-culture systems. Adv Drug Deliv Rev 94: 116-125.

Uygun BE, Stojsih SE, Matthew HWT (2009) Effects of immobilized glycosaminoglycans on the proliferation 
and differentiation of mesenchymal stem Cells. Tissue Eng Part A 15: 3499-3512.

Wissink MJB, Beernink R, Pieper JS, Poot AA, Engbers GHM, Beugeling T, Van Aken WG, Feijen J (2001) Immobilization of heparin to EDC/NHS-crosslinked collagen. Characterization and in vitro evaluation. Biomaterials 22: 151-163.

Yokoyama A, Gelinsky M, Kawasaki T, Kohgo T, König U, Pompe W, Watari F (2005) Biomimetic porous scaffolds with high elasticity made from mineralized collagen - an animal study. J Biomed Mater Res B Appl Biomater 75B: 464-472.

Yunus Basha R, T.S. SK, Doble M (2015) Design of biocomposite materials for bone tissue regeneration. Mater Sci Eng C 57: 452-463.

Zacchigna S, Tasciotti E, Kusmic C, Arsic N, Sorace O, Marini C, Marzullo P, Pardini S, Petroni D, Pattarini L, Moimas S, Giacca M, Sambuceti G (2007) In vivo imaging shows abnormal function of vascular endothelial growth factor-induced vasculature. Human Gene Therapy 18: 515-524.

Zwingenberger S, Langanke R, Vater C, Lee G, Niederlohmann E, Sensenschmidt M, Jacobi A, Bernhardt R, Muders M, Rammelt S, Knaack S, Gelinsky M, Günther KP, Goodman SB, Stiehler M (2016) The effect of SDF$1 \alpha$ on low dose BMP-2 mediated bone regeneration by release from heparinized mineralized collagen type I matrix scaffolds in a murine critical size bone defect model. J Biomed Mater Res Part A 104 (9): 2126-2134.

\section{Discussion with reviewers}

Timothy Douglas: Do the authors feel the modification of the scaffolds with heparin can aid in bone fracture repair alone, or would the scaffolds need to have the co-culture cells seeded onto them prior to implantation?

Authors: The scaffolds can be applied for bone fracture repair alone, extracorporeal seeding is not mandatory. This is important as the implantation of pre-seeded scaffolds poses problems, not only due to the insufficient oxygen and nutrient supply of the cells in the inner scaffold regions, as result of the lack of vascularisation immediately after implantation, but also due to the difficulties for cell containing tissue engineering constructs concerning the requirements for the authorisation as advanced therapy medical products (ATMP). Therefore, the focus of our work is on the development of scaffolds which will be colonized in situ, i.e. bioresorbable scaffolds specifically designed to recruit and accommodate endogenous cells upon implantation, to stimulate fast vascularisation and finally tissue formation and remodelling. Seeding of the scaffolds in the present study was done for in vitro characterisation of the influence of the heparin modification on the osteogenic and angiogenic cell response.

Timothy Douglas: Have you tested these scaffolds in vivo yet?

Authors: The unmodified scaffolds of mineralised collagen were tested in rat subcutaneously and in a femur bone defect indicating its suitability as an implant material for bone tissue regeneration (Yokoyama et al., 2005). A heparin-modified scaffold variant (P-75; post-modified with $75 \mathrm{mg}$ heparin per g collagen), loaded with BMP-2 and SDF- $1 \alpha$, was recently tested in a murine critical size bone defect model (Zwingenberger et al., 2016). This study demonstrated the potential of the scaffolds to enhance bone regeneration by local and sustained delivery of signalling factors. Currently, another in vivo study is in progress investigating the bone regenerative capacity of heparinmodified scaffolds (P-75) functionalised with cell culture supernatants from hypoxia-treated hBMSC.

Janos Kanczler: In which clinical applications do you see a need for the materials you are producing? Authors: In systemically altered bone (e.g. in case of osteoporosis), the regenerative capacity is strongly reduced - by an impaired balance between bone formation and resorption or due to a general reduction of the number of cells. In such a situation, scaffold materials which are able to attract cells with regenerative potential in the affected area, which stimulate cell proliferation, osteogenesis as well as angiogenesis could better support bone regeneration than established bone replacement materials.

Janos Kanczler: In vivo the surface of the biomaterial will be changed by the initial contact with biological tissues of the patient (or animal). Do you think your in vivo tests are predictive of the environment in which there is blood in contact with the biomaterial surface?

Authors: The first in vivo study with heparin-modified scaffolds of mineralised collagen (variant P75) demonstrated the suitability of the scaffolds for bone defect healing and for delivery of biologically effective signalling molecules mediating bone formation (Zwingenberger et al., 2016). However, the contact of the collagen-based scaffolds with blood could induce clotting which is expected to interfere with cell penetration. The heparin modification could help to locally decrease blood clotting at the scaffold surface - we plan to investigate that in vitro with human blood to be able to predict the behaviour after implantation.

Editor's note: The Scientific Editor responsible for this paper was Juerg Gasser. 